\title{
Formação profissional: mudanças ocorridas nos Cursos de Enfermagem, CE, Brasil
}

\author{
Professional formation: changes happened in Nursing Courses, CE, Brazil
}

Formación profesional: cambios ocurridos en los Cursos de Enfermería, CE, Brasil

\author{
Silvia Maria Nóbrega Therrien', Marcília Chagas Barreto', \\ Maria Irismar de Almeida", Thereza Maria Magalhães Moreiral"I \\ 'Universidade Estadual do Ceará. Mestrado Acadêmico em Saúde Pública. Fortaleza, CE \\ "Universidade Federal do Ceará. Fortaleza, CE \\ I'Universidade Estadual do Ceará. Mestrado Acadêmico Cuidados Clínicos em Saúde. Fortaleza, CE
}

Submissão: 13/09/2007

Aprovação: 12/02/2008

\section{RESUMO}

A investigação tem como objetivo compreender os novos cenários de formação da enfermeira nas instituições pedagógicas. Foram analisados os cursos de duas universidades do Estado do Ceará. Os dados foram escolhidos com base em relatórios, normas, documentos curriculares e entrevista com os coordenadores dos cursos. Os resultados demonstram Que os programas pedagógicos sofreram, nas últimas décadas, mudanças mais pontuais relacionadas às reformas decorrentes da Lei de Diretrizes e Base da Educação da Educação Nacional, das políticas de saúde e do mercado de trabalho.

Descritores: Educação; Enfermagem; Bacharelato em enfermagem.

ABSTRACT
The investigation has as objectives to understand the new scenarios of the nurse's formation in the teaching institutions. The courses of two universities of the State of Ceará were analyzed. The data were picked up of reports in normative and curricular documents, and you interview with the coordinators of the courses. The results demonstrate that in the teaching programs in certain decades of the history, it was identifying more punctual changes related with the reformations happened in the Law of Guidelines and Base of the Education (LDB), in the politicians of health and in the work market.

Descriptors: Education; Nursing; Education, nursing, baccalaureate.

\section{RESUMEN}

La investigación tiene como objetivos la comprensión de los nuevos escenarios de formación de la enfermera en las instituciones de enseñanza. Fueron analizados los cursos de dos universidades del Estado de Ceará. Los datos fueron recogidos de informes en documentos normativos y curriculares, e entrevistas con los coordinadores de los cursos. Los resultados demuestran que en los programas de enseñanza en determinadas décadas de la historia, fue identificando cambios más puntuales relacionados con las reformas ocurridas en la Ley de Directrices y Base de la Educación (LDB), en las políticas de salud y en el mercado de trabajo.

Descriptores: Educación; Enfermería; Bachillerato en enfermería. 


\section{INTRODUÇÃO}

Neste trabalho partimos do princípio de que a Qualidade profissional do serviço de enfermagem está estreitamente vinculada à conveniente preparação profissional. Embora as instituições formadoras também, no geral, comunguem desta percepção, o desafio de Qualificar a enfermeira tem percorrido um caminho longo e difícil. Por outro lado, a capacidade profissional da enfermeira está também articulada a uma formação profissional situada no contexto de trabalho e ainda a uma compreensão desse profissional como sujeito-reflexivo $^{(1-4)}$, aQuele Que constrói sua ação na própria situação vivenciada, Que vai além da racionalidade interativa. A partir dessa compreensão, esse estudo focaliza as mudanças ocorridas nos planos de estudos dos cursos de enfermagem e a exigência de Qualificação do seu corpo docente, em função do perfil desejado de profissional a ser formado. Tem como objetivos: compreender os novos cenários de formação da enfermeira no contexto das instituições de ensino, levando em consideração a larga trajetória histórica dessa prática profissional e as mudanças econômicas ocorridas no cenário político e social brasileiro; e verificar as mudanças ocorridas nas instituições de ensino de enfermagem no Ceará, com relação à implantação do novo currículo, Que ocorre em 1997ª, como proposta de formação desse profissional.

\section{METODOLOGIA}

Para a consecução dos objetivos, foram analisados os cursos de enfermagem das duas universidades públicas mais antigas do Estado do Ceará: a Universidade Estadual e a Universidade Federal do Ceará.

Foi realizada análise dos documentos normativos e curriculares dos referidos cursos e entrevistas semi-estruturadas com os coordenadores dos cursos. As entrevistas versaram sobre o período de 1997 a março de 2004, época de implantação do "novo" currículoa, e de reQualificação do corpo docente das universidades. As Questões éticas foram seguidas conforme Resolução 196/96.

${ }^{a}$ Enquanto os cursos de Enfermagem já estavam implantando seus "novos" currículos, o MEC, por outro lado, tinha aprovado através da Lei de Diretrizes e Bases da Educação Nacional-LDB, em dezembro de 1996, uma ampla reforma do sistema educacional com a Lei 9.394/96. Esta Lei traz entre outras mudanças a introdução de diretrizes curriculares, substituindo-as pelo conceito de fixação de currículo mínimos. Os currículos, entretanto continuam sendo implantados, uma vez que somente em 9 de novembro de 200I, o Conselho Nacional de Educação/Câmara do Ensino Superior instituiu as Diretrizes Curriculares Nacionais do Curso de Graduação em Enfermagem. A partir já de finais do ano de 200I, se inicia uma nova reestruturação, Que é construída em cada escola que passa a produzir o seu Projeto Político Pedagógico. Essas mudanças atingiram todas as profissões de nível superior (COFEN (BR), 1996; Ministério da Educação (BR), 1996:2000:2002).

Conselho Federal de Enfermagem. Publicação Oficial. Abril/junho. Boletim. Ano XIX n. 2. 1996.

Ministério da Educação (BR). Lei 9.394, de 20 de dezembro de 1996 : estabelece as diretrizes e bases da educação nacional. Diário Oficial [da] União. Brasília (DF) 1996. dez.2; 34(248) seção 1:27, 883-4I.

Ministério da Educação (BR). Secretaria da Educação Superior. Enfrentar e vencer desafios. Brasília (DF), 2000.

Ministério da Educação (BR). Resolução CEB/CNE n.4. 2002.)

\section{RESULTADOS E DISCUSSÃO}

Formação da Enfermeira e Trajetória Profissional: Cenário Econômico e Político em Diferentes Épocas

Os anos 20 foram o marco do ensino de enfermagem no Brasil com a criação da primeira escola de enfermagem - Ana Nery. Superava-se, assim, a enfermagem praticada por voluntários, escravos e religiosas. Na Escola ministrava-se o ensino médio e profissional, com influência inglesa e norte-americana. Objetivavase preparar a enfermeira para saúde pública, visando, sobretudo, o saneamento dos portos e a profilaxia das doenças transmissíveis.

Contava-se com um cenário político-econômico promissor, voltado para exportação, o Que ampliava a importância dos portos e a necessidade de mantê-los fora do alcance da febre amarela e de outras doenças transmissíveis. Sob os auspícios das reformas de Carlos Chagas criou-se a possibilidade de Qualificação de pessoal para o desenvolvimento dessa nova política sanitária, o Que implicou no surgimento da enfermagem como profissão institucionalizada ${ }^{\mathrm{b}}$.

Nos Anos 30, intensificou-se a criação de escolas de enfermagem impondo a necessidade de criação do padrão de formação Ana Nery, uma vez que "a profissionalização da enfermeira se constituiu em uma prática homogênea em mãos de agentes diversos, submetidos a treinamentos distintos"(5).

A duração do curso foi, inicialmente, de três anos letivos, conforme estabelecia o Decreto no 16.300/23 da Escola do Departamento Nacional de Saúde Pública, passando a ter Quatro anos letivos, já em seu segundo ano de existência. Dividido em cinco partes, a última delas era destinada à especialização que poderia ocorrer: em enfermagem clínica, saúde pública ou administração hospitalar. Nesta fase conviviam a formação para saúde pública e hospitalar. O cenário à época apontava para o inicio do processo de industrialização e urbanização de grandes parcelas da população.

Nos anos 40/50 a tônica da enfermagem passou a ser hospitalar em detrimento da saúde pública. Os trabalhadores, agora urbanos, protegidos por sistema de seguridade social, reivindicavam atendimento para todos nos hospitais. Nesse sentido a formação de enfermagem era a hospitalar com predomínio da aprendizagem técnica. Eneuanto em 1943 de 334 enfermeiras, 66\% trabalhavam na saúde pública e 9,5\% em hospitais, em 1950, 49,4\% das enfermeiras atuavam em campo hospitalar e 17,2\% na saúde pública $^{(6)}$.

Nos anos 60, com a Reforma Universitária, implantou-se a formação superior em enfermagem, o reconhecimento da carreira da enfermeira em seus três níveis: superior, técnico e auxiliar (LDB 4.024/61). Em 1962, legislação específica promoveu o então ensino médio para superior. Objetivava-se a ampliação das funções da enfermeira, além das funções assistenciais, acresciam-se as

\footnotetext{
${ }^{b}$ Como antecedentes específicos mediatos do aparecimento da enfermagem profissional no Brasil, temos a Fundação, em 1916, da Cruz Vermelha Brasileira, fruto de um movimento internacional, para melhorar as condições de assistência aos feridos da Primeira Guerra Mundial e o início do curso intensivo para enfermeiras visitadoras junto ao Departamento Nacional de Saúde Pública, em 192 I (Carvalho, 1972).

CARVALHO, A. C. de. Orientação e ensino de enfermagem no campo clínico.Tese de Doutoramento. 1972.
} 
administrativas e as de docência ${ }^{(5,7)}$.

O ensino da técnica em si vai dando lugar ao ensino da técnica com fundamentação científica. A predominância continua na formação curativa. A disciplina de saúde pública passa a ser não obrigatória no currículo mínimo. Comparando os currículos de 1949 e 1962, o primeiro surge numa fase em Que prevalecia o espírito político supostamente liberal, com um capitalismo Que ainda comportava a privatização da saúde de forma empresarial, privilegiando as enfermidades de massa pelas disciplinas nos currículos Que enfocavam a área preventiva. O segundo surge num momento em Que a economia brasileira começa a mostrar um processo concentrador de renda, o Que leva a preocupação primordial do currículo de enfermagem para a formação de profissionais para o trabalho também em clínicas especializadas ${ }^{(8)}$. No cenário de então observa-se a ampliação das instituições de previdência social e crescimento da área curativa hospitalar.

Nos anos 70, cenário de controle dos movimentos sociais, mantém-se a exclusão da saúde pública do currículo mínimo. O movimento de prevenção da saúde nas Escolas de Enfermagem, com apoio da política de extensão de cobertura e do direito à saúde, desenvolvida pela OMS/OPAS (com base em documentos da OMS, OPAS, MS, MEC) não foi capaz de se contrapor à tendência de formação curativa Que já vinha de décadas anteriores. A formação se concentrava nas ciências biológicas e fisiológicas e a formação para atuação em clínicas especializadas e curativas atendia aos anseios da indústria farmacêutica e de equipamento médico-cirúrgico ${ }^{(9)}$.

Nos anos 80, a formação nas escolas passou a se voltar para a área hospitalar e para a saúde pública. Era uma resposta à ideologia da prevenção adotada pelos movimentos iniciados na década anterior, Que se juntou ao movimento sanitário de saúde pública; a Reforma Sanitária e a proposta SUDS. Mudanças Que sinalizam para o Início de revisão das funções da enfermeira. No cenário, entretanto, ainda subsiste a medicina curativa hospitalar como maior empregador. É forte a Indignação com as condições de saúde e mercantilização do setor pelos profissionais e sociedade civil.

Nos anos 90/2000 identifica-se mais claramente uma busca de (re)definição das funções da enfermeira; visando reconhecimento e autonomia. Uma adeQuação de currículos às novas políticas e sistema de saúde SUDS/SUS. Uma busca mais concreta de legitimação da enfermeira como profissional independente com atuação nas áreas de assistência, gerência, ensino e pesQuisa. O cenário conta com a concretização da implantação da nova proposta de sistema de saúde, SUS, com a municipalização e distritalização desse sistema, com maior autonomia para os estados e municípios. Observa-se a volta de algumas doenças endêmicas como a dengue, e no cenário farmacêutico surge a conquista dos genéricos. Constata-se ainda com o SUS, os processos de implantação e consolidação dos Conselhos de Saúde e a presença da exclusão social e dos danos ambientais.

\section{Formação da Enfermeira no Contexto das Instituições de Ensino UECE e UFC}

No Ceará, a formação da enfermeira não foi distinta do restante do país, ali também as irmãs de caridade foram às precursoras da profissão de Enfermagem. O ensino oficial de enfermagem no Ceará obedeceu a uma diretriz geral Que regula os planos de estudos em todo o país (hoje Projetos Políticos Pedagógicos-PPP) e Que encontra na legislação federal do Ministério da Educação suas bases legais.
Em 1943 foi criada a primeira escola de enfermagem do Ceará e do Nordeste e recebeu o nome de Escola de Enfermagem São Vicente de Paulo. Funcionou agregada à Universidade Federal do Ceará até 1956, passando a compor a Universidade Estadual do Ceará no ano de $1975^{(10)}$.

Existem atualmente, no Estado, sete cursos de Enfermagem de nível universitário, dos Quais três se encontram em universidades do interior do Estado (dados referentes ao mês de dezembro de 2004). A média de enfermeiras formadas por ano é de 520 profissionais.

A inserção do curso de enfermagem na universidade, entre outras Questões, permitiu a participação da enfermeira em três importantes campos: a docência, a gestão e a investigação. Trouxe novos sinais de identidade, incluindo a palavra 'enfermeira' na nova titulação, o Que supõe a modificação dos Questionamentos Que a partir desse momento orientaram a educação e regularam a elaboração dos planos de estudos, voltados para formar esse profissional. Os aspectos gerais do plano de estudos de cinco destes cursos implantados em $1997^{\circ}$ são: duração mínima de 4 anos de estudos; carga horária a partir de 4.200 horas/aula; nível médio e aprovação no vestibular como pré-reQuisitos; objetivos gerais para cada uma das áreas/matérias; determinação das disciplinas Que farão parte de cada curso e a área específica a Que pertencem.

Os cursos de enfermagem oferecidos nas sete universidades cearenses, como ocorre no resto do país, são todos dirigidos por enfermeiras(os). As disciplinas específicas da área de enfermagem só podem ser ministradas por enfermeiras(os). As demais disciplinas são ministradas por profissionais das áreas de estudo correspondentes.

Há um plano de estudos para estes cursos Que obedece a uma regulamentação do Conselho Federal de Educação pela Portaria n. 1.72 1/1994 do SESU/MEC. Em âmbito nacional, há o currículo mínimo, Que define diretrizes básicas, tais como: duração dos estudos; distribuição teórico-prática e conteúdos gerais. Cada Escola/Curso, por sua vez, faz as adaptações necessárias a este plano, formulando então o Currículo Pleno. Para tanto, consideram sua natureza e "vocação"; o perfil do profissional enfermeiro a ser formado; os marcos conceituais adotados para cada um(a) deles(as); as características regionais e necessidades de serviços locais e da população onde o curso está instalado. Uma exigência maior é Que se organize o ensino, estabelecendo relação entre a teoria e a prática, principalmente no Que se refere ao ensino das clínicas.

Tanto os cursos de enfermagem mais antigos no Estado - os da Universidade Estadual do Cearád e Universidade Federal do Cearáe

'Que introduziram as mudanças no currículo a partir de 1997, e Que atualmente aguardam aprovação de seus Projetos Político Pedagógico-PPP no Conselho das Universidades ou Faculdades. Os demais cursos foram aprovados recentemente pelo MEC e portanto já iniciaram com o seu PPP estruturado com base na LDB/ 96 e nas Diretrizes Curriculares Nacionais do Curso de Graduação em Enfermagem aprovada em 9 de novembro de 200 I pelo Conselho Nacional de Educação/ Câmara do Ensino Superior.

${ }^{d}$ Criado em 1943, na época Escola São Vicente de Paulo. Reconhecido no ano de 1946. Anexado em 1977 à Universidade Estadual, através do Parecer $n^{\circ}$ 764/77 do Conselho Federal de Educação.

${ }^{e}$ Criado em 1970, conforme Resolução no 230 - A, de 23 de novembro de 1970. No ano de 1976, foi autorizada sua implantação, sendo posteriormente reconhecido pela Portaria Ministerial No I. I60, do Diário Oficial da União de $21 /$ $I I / 1979$. 
,- Quanto os demais fundados nas décadas de 80, 90 e anos 2000 estão adotando, desde 1997, um novo currículof com base na proposta do modelo atual de assistência à saúde. Este modelo é regulamentado pela Portaria já citada de $n^{\circ} 1.721$, de 15 de dezembro de 1994, do Ministério da Educação, Que estrutura o conteúdo mínimo e duração do curso de graduação em enfermagem para o país como um todo . Esta portaria, entre outras atribuições, determina as diferentes áreas temáticas nas Quais devem estar contidas as matérias e disciplinas relativas a ciências biológicas e humanas, indicando carga horária, créditos e percentuais que devem corresponder a cada área, assim estabelecidos: horária

- Bases Biológicas e Sociais de Enfermagem: 25\% da carga

- Fundamentos de Enfermagem: 25\% da carga horária

- Assistência de Enfermagem: 35\% da carga horária, onde se incluem obrigatoriamente os conteúdos teórico-práticos.

- Administração em enfermagem: 15\% da carga horária (conteúdos teórico-práticos).

- Depois de cumpridos todos os créditos, fixa a obrigatoriedade de desenvolvimento das atividades de campo prático supervisionado, em hospitais, ambulatórios e rede básica dos serviços de saúde.

A partir deste currículo mínimo, cada instituição faz as adaptações regulamentares segundo seus recursos e interesse. O currículo mínimo contém 3.500 horas/aula previstas em Portaria Ministerial. O curso da Universidade Estadual, por sua vez, conta com um currículo pleno de 4.200 horas/aula e o da Universidade Federal, com 4.230 horas/aula. Há, portanto, um espaço significativo de 700 horas/aula para Que cada curso faça suas adaptações, para a formação do profissional enfermeiro egresso destes cursos.

A proposta de currículo mínimo para o Curso Superior de Enfermagem, fruto de um longo processo iniciado em nível nacional no ano de 1986, e implantada em 1997 nos cursos de enfermagem cearenses, trouxe expectativas de solução de diversos problemas relacionados à saúde e, sobretudo, à profissão. Os egressos Que vivenciaram essa nova proposta estão chegando ao mercado de trabalho desde o ano de 200 I. Uma avaliação dessa realidade de formação e atuação merece uma investigação.

\section{A Realidade dos Cursos de Formação: Análise e Discussão dos Dados}

\section{Currículo/Plano Pedagógico: concepções diversas e como resultado o profissional a ser formado na Universidade Estadual do Ceará-UECE e Universidade Federal do Ceará-UFC}

O currículo pleno, formulado a partir da realidade e do interesse de cada Curso/Escola, é resultado da definição de profissional a ser formado. A compreensão desse profissional, de sua função e de

fanteriormente a este currículo novo, existia em exercício o currículo estabelecido pelo Parecer 163/I972, Que regulamentava o currículo mínimo do curso de enfermagem depois de sua introdução na Universidade, ocorrida em 1962 e implementada em 1968, por ocasião da Reforma Universitária. Este mesmo currículo foi modificado no ano de 1982, em âmbito nacional, ocasião em que se reorganizaram as disciplinas, acrescentaram-se e retiraramse outras do ciclo básico, bem como introduziu-se a Monografia como prérequisito ao curso de bacharelado. onde vai realizar sua atuação, apresenta enfoQues diversos.

Há compreensões de Que o plano deve partir das experiências diárias dos próprios alunos. Outras tendências advogam que deve ser centrado na resolução de problemas de complexidade crescente. E ainda outros, Que deve ser organizado em matérias, agrupando as enfermidades em torno do problema e com a aprendizagem concentrada nos hospitais. Este último modelo é o que mais se aproxima do adotado atualmente no Curso de Enfermagem da Universidade Estadual do Ceará.

Há ainda planos Que utilizam um enfoQue da medicina centrada no paciente, família ou comunidade, onde os estudantes começam pelos problemas simples de saúde, identificados no domicílio, partindo depois para assistência no centro de saúde, depois para o hospital regional e finalmente para o hospital especializado, Que indica o final de sua assistência. É este o plano em Que melhor se eneuadra o Curso de Enfermagem da Universidade Federal do Ceará.

Todos estes modelos podem formar enfermeiras competentes e os programas de Qualeuer duração sempre dependeram em grande medida da inteligência, do caráter, forma física, educação anterior e experiência social dos alunos ${ }^{\prime \prime}$.

O Plano de Estudos dos Cursos de Enfermagem das duas universidades desse estudo encontram-se divididos em 9 semestres letivos. O Curso ministrado pela Universidade Estadual tem como objetivo formar o enfermeiro com uma visão orientada para a saúde da população, capacitando-o para atuar nos processos de saúde e enfermidade, em todas as fases evolutivas do homem.

No curso da UECE, sobre o perfil do profissional egresso desse curso, ele é inicialmente generalista. Um profissional que possa ser capaz de fazer uma leitura crítica e reflexiva da realidade Que vivencia e Que possa intervir nas várias dimensões do ciclo vital e em vários aspectos, como emocionais, sociais, econômicos, biológicos, ou seja, contemplando as necessidades do ser Que assiste (relato da coordenadora do Curso em março de 2004).

O Curso da Universidade Federal adota marcos conceituais mais pontuais Que abordam o conceito de homem, sociedade, saúde, política, enfermagem, cuidado e família.

Na UFC, com relação ao perfil do profissional egresso, este deve ter um nítido conhecimento dos conteúdos fundamentais de cada disciplina de modo que possa adequar este conhecimento a cada área de trabalho. Com relação à tendência Que influencia o marco conceitual do curso, este ainda é muito marcado pelos fundamentos da reforma sanitária, mas precisa ser adequado ao objeto de trabalho de enfermagem - o individuo no contexto familiar, social, político, etc (relato da coordenadora do Curso em março de 2004).

A partir dessa compreensão, os dois cursos contemplam, sobretudo, a Quantidade de horas e créditos Que seus alunos devem cumprir nos campos de prática, onde o saber de fato se complementa e se concretiza. O Curso da Universidade Estadual, em seu Currículo Pleno, contempla a prática em três redes de ação. A Rede Básica de Saúde, com 300 horas e 20 créditos; a prática na Rede Ambulatorial, com 150 horas e 10 créditos, e a prática na Rede Hospitalar, com 450 horas e 30 créditos.

Por outro lado, o Curso da Universidade Federal divide seus campos de prática em Quatro áreas, assim denominadas: Comunitária Urbana; Hospitalar Urbana; Área Rural e Área Eletiva. Cada área 
corresponde a 260 horas e 16 créditos. Fica clara a linha Que demarca um curso e outro. Um situa-se no campo preventivo, com a concentração de 520 horas (32 créditos) nas áreas comunitárias urbanas e rurais; o outro, no campo hospitalar, com 450 horas (30 créditos), acrescentando a estas a prática na Rede Ambulatorial, onde a assistência é em parte hospitalar, com 150 horas (10 créditos). Mas, embora o curso da Universidade Estadual tenha redirecionado alguns de seus conteúdos e disciplinas, o perfil do profissional graduado encontra forte referência na área assistencial e curativa.

As disciplinas que compõem o Plano de Estudos em Enfermagem, no currículo antigo, estavam agrupadas por disciplinas ${ }^{\circ}$ obedecendo a uma seeüência gradual e racional para ser solicitada e cursada pelos alunos. Esse controle era, e ainda se faz, mediante a exigência dos pré-requisitos necessários que todo aluno deve ter para cursar outra disciplina e outro semestre. lá no currículo novo, as disciplinas estavam agrupadas em áreas. Como no currículo antigo, ainda se segue a orientação segundo a Qual as disciplinas, agora agrupadas em áreas temáticas, devem favorecer experiências de aprendizagem em complexidade crescente, Que possibilitam ao aluno, em seu término, a integralidade do processo de formação.

$\mathrm{Na}$ verdade, o currículo antigo contribuía para uma visão fragmentada do homem e da saúde e os conteúdos enfocavam o estudo dos aparelhos e sistemas. No novo, praticamente (re)organizaram-se as disciplinas existentes em matérias/áreas. Resta investigar, na prática, se essa nova configuração contribuiu para uma visão contextualizada do indivíduo a ser assistido e da assistência a ser prestada. No discurso das coordenadoras se percebe essa intenção/compreensão.

Houve aumento na oferta de disciplinas na área de ciências humanas, com a introdução da sociologia e filosofia mais articuladas com a saúde, favorecendo uma formação mais humanística, com enfoques holísticos. Embora sejam Planos de Estudos mais orientados para uma prática preventiva, de atenção primária, como é o da Universidade Federal e outro para o trabalho mais hospitalar, como é o da Universidade Estadual, não se observa em um Plano/ Curso ou outro, diferença de níveis, senão nos enfoQues prioritários de seus conteúdos. Enquanto um deles privilegia a distribuição da carga horária e créditos para áreas de saúde pública, o outro reserva mais carga horária e créditos para aprendizagens clínicas.

A preparação do corpo docente das universidades para implantação e implementação desse currículo, segundo informações de suas coordenadoras, tem ocorrido, na Universidade Estadual, por meio de seminários e oficinas pedagógicas, para gerar discussões e realizar ajustes Objetiva-se a integração entre as áreas demarcadas no currículo e conseqüentemente adequação dos conteúdos de cada área. Há um processo de (re)estruturação do novo currículo de cada curso e Que pretende ser implantado já no ano de 2005. Essa reestruturação responde às exigências da nova $\mathrm{LDB} / 96$ e, segundo informações da coordenadora, é fruto das avaliações realizadas com professores e alunos e resultado direto da experiência vivenciada por esse grupo em sala de aula e nos campos de prática. Os trabalhos vêm sendo desenvolvidos há mais de três anos e visam sair da concepção de currículo para elaboração de Projeto Político Pedagógico do próprio Curso.

A coordenadora da UFC afirma Que não houve adeQuações na grade curricular implantada em 1997, mas nos planos de disciplinas. As ementas não foram alteradas, nem houve introdução de disciplinas novas. Para ela, há necessidade de avaliação do novo plano, o Que não foi possível de realizar, pelo número diminuto de docentes e a decorrente sobrecarga de trabalho. Encontra-se também em fase final de elaboração de seu Projeto Político Pedagógico.

\section{Corpo Docente: Trajetória de Qualificação na UECE e UFC}

O Curso de Enfermagem da Universidade Federal contava, por ocasião do início da implantação do novo currículo em 1997, com 3 I docentes, e o da Universidade Estadual, com 38 docentes, todos professores efetivos nas duas instituições. Em março de 2004, esse cenário se encontra bastante modificado, como pode ser observado no Tabela 1.

Os dados postos nestaeTabela refletem uma expressiva mudança,

Tabela 1. Número de profesores dos cursos de enfermagem da UECE e UFC e sua titulação correspondente. Fortaleza, CE, $1997-2004$.

\begin{tabular}{|c|c|c|c|c|c|c|c|c|c|c|}
\hline \multirow{3}{*}{ Universidades } & \multicolumn{10}{|c|}{ Titulação/Ano } \\
\hline & \multicolumn{2}{|c|}{ Doutor } & \multicolumn{2}{|c|}{ Mestre } & \multicolumn{2}{|c|}{ Especialista } & \multicolumn{2}{|c|}{ Graduado } & \multicolumn{2}{|c|}{ Total } \\
\hline & 1997 & 2004 & 1997 & 2004 & 1997 & 2004 & 1997 & 2004 & 1997 & 2004 \\
\hline UECE & 3 & 11 & 10 & 17 & 23 & 1 & 2 & - & 38 & 29 \\
\hline UFC & 7 & 19 & 21 & 3 & 3 & - & - & - & 31 & 22 \\
\hline Total & 10 & 30 & 31 & 18 & 26 & 1 & 2 & 0 & 69 & 51 \\
\hline
\end{tabular}

UECE: em 2004, refere seis professores substitutos com titulação de mestre. UFC: em 2004, refere II professores substitutos com grau de mestre.

gAnteriormente, o Curso de Enfermagem estava dividido em disciplinas Que pertenciam ao Ciclo Básico e ao Ciclo Profissional. No Ciclo Básico, as disciplinas eram: Biologia Celular e Molecular, Filosofia Geral e da Ciência, Química Orgânica, Matemática Aplicada a Biologia, Sociologia Geral, Técnicas Gerais de Laboratório etc. E as disciplinas pertencentes ao chamado Ciclo Profissional eram todas relativas ao exercício de enfermagem. tanto no numero de professores efetivos das duas universidades, Quanto nas suas respectivas titulações. Ambas Universidades perderam professores efetivos, no período. Atualmente estas universidades trabalham com a categoria do professor substituto Que é contratado, através de processo seletivo, para ministrar aulas por um período de I ano, prorrogável por mais I ano. As dificuldades 
oriundas do trabalho com professores Que não têm estabilidade na instituição se refletem diretamente na implementação do Currículo novo e irão se refletir no PPP do Curso, em tramitação.

Com relação à titulação do corpo docente, observa-se nos dados da Tabela I uma significativa mudança Que pode ser atribuída em parte, à chegada dos primeiros grupos oriundos do Mestrado em Saúde Pública e do Mestrado em Saúde da Criança e do Adolescente da Universidade Estadual e, principalmente, do Mestrado e Doutorado em Enfermagem da Universidade Federal. O numero de enfermeiras com titulação de doutor passa nas duas universidades de 10 em 1997 para 30 em 2004. Pode-se inferir, a partir desse resultado, a importante contribuição desse grupo para o ensino de graduação, como também para a implantação do novo Plano de Ensino do curso de graduação e, sobretudo, para a pesQuisa e pós-graduação.

Outros pontos importantes podem ser aqui levantados para reflexão e discussão Quanto à implantação de um Plano de Ensino. A formação não ocorre somente na universidade; há a necessidade de se pensar uma proposta de currículo concebido para assegurar a terminalidade do processo de formação e uma compreensão do profissional como sujeito reflexivo.

Quase toda a formação prática da enfermeira ocorre fora dos muros da universidade. Se os cursos contam com dificuldades (número inadequado de professores, professores com contratos temporários, outros), contudo, a situação precária dos campos de prática, onde grande parte desta formação ocorre, são fatores Que também apresentam limitações significativas para esta formação.

Sabe-se Que as instalações e os recursos clínicos devem dar a oportunidade ao estudante de confrontar-se com os problemas e situações de enfermagem ${ }^{(11)}$. Sabe-se, também, Que as deficiências pelas Quais passa o setor público brasileiro afetam os hospitais e postos de saúde, onde se observam, entre outros fatores, instalações e equipamentos precários, carência de profissionais e auxiliares em termos Quantitativos e Qualitativos. Tais condições interferem e desQualificam a maioria dos campos para a prática dos alunos.

Entretanto, são poucos os hospitais públicos Que realizam a assistência à saúde com utilização de novas tecnologias em máeuinas e equipamentos. É importante colocar esta Questão, uma vez Que "a introdução de novas tecnologias no processo produtivo e de serviços implicaria em mudanças na organização do trabalho; estes, por sua vez, supõem maior necessidade de Qualificação dos trabalhadores e, portanto, novas exigências de formação"(12). A relação entre educação-formação e o mundo do trabalho é complexa a partir de muitos pontos de vista. De Pablo ${ }^{(12)}$ identifica neste campo Quatro principais áreas temáticas: as exigências Que o sistema produtivo coloca para o mundo da educação; a problemática do mercado de trabalho e suas repercussões sobre a inserção do trabalho dos jovens; a necessidade de mudança e transformação no funcionamento interno do próprio sistema educativo e a participação concreta de centros educacionais e empresas na formação profissional do jovem, trabalha com dois destes campos: as exigências Que o sistema produtivo faz ao mundo da educação e a necessidade de mudanças e transformação em funcionamento desse mesmo sistema.

Em geral, o Que temos observado é Que as instituições de serviços de saúde do Estado, pelos pontos negativos identificados, não têm se constituído em um lugar favorável à aprendizagem e formação das enfermeiras. Entretanto, têm contribuído para Que elas entrem em contato com a realidade de trabalho Que as espera, uma vez Que são as instituições públicas no Brasil as que mais empregos oferecem aos egressos destes cursos.

Quanto à Questão Que envolve a compreensão de uma proposta de currículo concebido para assegurar a terminalidade do processo de formação, ressaltamos ${ }^{(13)}$ : o currículo deve assegurar a terminalidade do processo de formação do enfermeiro, excluindo do nível de graduação a tendência à falsa especialidade. Este pressuposto gera um principio orientador de um currículo mínimo estruturado de forma contínua, com duração em tempo e horas compatíveis com um perfil profissional competente para atuar, preferencialmente, na rede básica dos serviços de saúde,

Chamamos atenção para compreensão do Que seja "terminalidade", devido à complexidade da nossa realidade em constantes mudanças. Como responder às exigências ou desafios Que são postos na prática diária da enfermeira, seja ela realizada na rede básica dos serviços de saúde ou ainda nos hospitais, faculdades, etc. Acreditamos Que a instituição deve ensinar as competências mínimas para o exercício da profissão ${ }^{(14,15)}$. Entendemos Que o ensino da ciência aplicada e a formação da enfermeira devem ser articulados objetivando a formação para reflexão-ação de modo Que o profissional seja preparado para os desafios Que a prática (o trabalho) exige.

Observa-se Que o ensino de enfermagem tem se apoiado em tendências marcadas pela adoção de modelos mecanicistas, associados a enfoques biológicos, presentes nas disciplinas de seu currículo. Com algumas exceções, tem-se enfatizado a repetição e a memorização das técnicas e procedimentos, e não a compreensão e a crítica do processo de trabalho como um todo. No entanto, a proposta do Novo Plano de Estudos iniciado em 1997.I nos dois cursos de Enfermagem analisados e a proposta já implantada nos cursos em todo o Brasil pretende mudar esta formação tradicional, em um sentido que envolva a assistência, a gerência, o ensino e a pesQuisa. Trata-se de uma mudança Que busca clarear e legitimar a função da enfermeira como profissional independente nas atividades anteriormente relacionadas, delimitando sua área de colaboração junto à equipe de saúde e de ação e supervisão junto à equipe de enfermagem.

Hoje, chega-se a um momento em Que o profissional de enfermagem deve alcançar a máxima autonomia e controle de sua prática, tornando-se um profissional para Quem os elementos de criatividade superem a subordinação e obtenham aceitação da sociedade $^{(16)}$. Acreditamos Que um dos mais importantes caminhos para se enfrentar o desafio encontra-se na formação Que inclui a participação da enfermeira na docência, na gestão e na investigação, na universidade, nos serviços de saúde e nas políticas de saúde.

\section{ALGUMAS CONSIDERAÇÕES}

A trajetória histórica de formação da enfermeira ocorreu atrelada às reformas das Leis de Diretrizes e Bases da Educação Nacional, acompanhando sempre as mudanças nas políticas de saúde e no mercado de trabalho.

A análise das diferentes disciplinas do currículo dos cursos de enfermagem revela Que até 1996 eles têm se apoiado predominantemente em tendências marcadas pela adoção de modelos mecanicistas associados a enfoques biológicos, o que 
contribui para uma visão fragmentada de homem e da saúde.

Contudo, a partir de 1997, o currículo novo propõe um processo de formação com base no modelo de assistência à saúde, com a proposta de legitimar a função da enfermeira como profissional independente nas áreas de assistência, gerência, ensino e pesQuisa, com busca de uma visão ampla de homem e saúde e reorganização das disciplinas por áreas. Esta concepção permite estabelecer e delimitar sua área de colaboração junto à equipe de saúde e definir seu campo de ação e de supervisão junto à equipe de enfermagem.

Ambas as universidades investigadas apresentaram discursos e compreensões semelhantes de perfil de profissional generalista, com percepção holística de homem, capaz de atuar com competência ampla de função e ação, no contexto familiar, social e político. Evidencia-se, assim, um ideal de difícil consecução, em termos de formação.

As universidades, entretanto, apresentam tendências diferentes na estrutura do currículo em conteúdos e áreas, carga horária e créditos. Há compreensão de currículo com terminalidade de formação, reafirmando a possibilidade de Que o profissional deixe a universidade totalmente formado para o trabalho. Tais compreensões não levam em consideração a enfermeira como sujeito reflexivo, nem a inclusão de outros saberes na sua formação.

Todavia, com a implantação do novo currículo, a UECE aponta para um perfil de profissional preparado para atuar nas áreas clínicas e hospitalares, enQuanto Que a UFC privilegia a formação na área de saúde pública. Os docentes da UFC apresentam maior nível de Qualificação. Observa-se, porém, Que o corpo docente das duas universidades encontra-se em processo de Qualificação, conforme indicam os dados referentes aos anos de 1997 a 2004. A contratação do professor substituto tem dificultado a implantação do novo currículo.

No processo de implantação do currículo novo, a UECE tem procurado integrar o grupo de professores por áreas temáticas e propõe mudanças para o currículo de 2004 no PPP de seu curso. A UFC tem trabalhado com adeQuações de conteúdos das disciplinas.

O desempenho profissional das enfermeiras formadas nas duas universidades e que entraram no mercado de trabalho a partir de 2002, apresenta perspectivas positivas, mas é necessário um processo de avaliação sistemática.

\section{REFERÊNCIAS}

I. Perrenoud P, Paquay L, Altet M, Charlier E. Formando professores profissionais. Quais estratégias? Quais competências? Porto Alegre (RS): Artmed; 2001.

2. Schön D. Educando o profissional reflexivo: um novo design para o ensino e a aprendizagem. Porto Alegre (RS): Artes Médicas; 2000.

3. Fenstermacher GD. The place of science and epistemology in Schon's conception os reflective practice. In: Grimment PP, Erickson GL. Reflection in teacher education. New York (NY): Theachers College Press; 1988. p. 36-46.

4. Fenstermacher GD; Richardson V. L'explicitación et la construction des arguments pratioues dans l'enseignement. Cahiers Rech Education 1994; I(I): 157-8I.

5. Silva GB. Enfermagem profissional: análise crítica. São Paulo (SP): Cortez; 1986

6. Almeida MCP. Contribuição ao estudo da prática de enfermagem. Ribeirão Preto (SP): USP/Escola de Enfermagem; 1981.

7. Nakamae DD. Novos caminhos da enfermagem: por mudanças no ensino e na prática da profissão. São Paulo (SP): Cortez; 1987.

8. Germano RM. Educação e ideologia em enfermagem no Brasil,
São Paulo (SP): Cortez; 1984.

9. Illich I. A expropiação da saúde: nêmesis da medicina. Rio de Janeiro (RI): Nova Fronteira; 1975.

10. Frazão ES. Trinta anos: Escola de Enfermagem São Vicente de Paulo. Fortaleza (CE); 1973.

11. Henderson VA. La naturaleza de la enfermería: reflexiones 25 años después, Madrid, Interamericana-MaGraw-Hill. 1994.

12. De Pablo. Hacia una formación profesional "concertada". Sociología del Trabajo. Nueva Época 1994; 22: 6-89.

13. Rodrigues A M. Subsídios para elaboração de uma proposta de currículo mínimo para a formação do enfermeiro. Rev Bras Enferm 1988; 4 I (3/4): 179-82.

14. Tardif M. Saberes docentes e formação profissional. Petrópolis (RI): Vozes; 2002.

15. Therrien J. Saber da experiência, identidade e competência profissional: como os docentes produzem sua profissão. Rev Contexto Educação 1997; 12(48): 7-36.

16. Martinez C, González NS. El siglo XX: hacia la consolidación de la profesión enfermera. In: Martín FF, coordenador. Historia de la enfermería en España: desde la antigüedad hasta nuestros días. Madrid (ESP): Síntesis; 1996. p. 287-98. 